\title{
VISUAL DEFECTS IN CASES OF DOWN'S SYNDROME AND IN OTHER MENTALLY HANDICAPPED CHILDREN* $\dagger$
}

\author{
BY \\ P. A. GARDINER \\ Department of Ophthalmology, Guy's Hospital, London
}

THIS study is based on a survey of children of school age attending a Junior Training Centre. Considering the difficulty of assessing both the visual acuity and the significance of ocular defects in these children, it is not surprising that the school doctors should have asked for a special investigation of the problem. Formal visual acuity estimations and ophthalmic supervision such as is provided for children in ordinary schools had not been undertaken, so that the teaching staff did not know how great a part visual defects might be playing in the children's behaviour and educability.

\section{Material}

62 children between the ages of 5 and 16 years attended the centre. All but two permitted examination, though it was not possible to assess visual acuity in every case and detailed examination of the fundi and of ocular movements was too difficult in some. Their intelligence quotients ranged from 30 to 50 and they were therefore below the educationally subnormal level. Only those defects which might limit visual acuity or function were looked for, so that anomalies such as Brushfield's spots, epicanthus, etc., were not recorded.

Of the 60 children examined, 22 suffering from Down's syndrome (mongolism) formed an easily recognizable group, leaving 38 others for comparison.

\section{Results}

Attempts were made to refract all these children under mydriasis, but in five of the miscellaneous group and three of those with mongolism no refractive data were obtainable. One of these was a 4-year-old mongol suffering from lens opacities too dense for refraction, and another in the miscellaneous group was certified as blind with aphakia.

Three other mongols had structural lesions: unilateral cataract, unilateral choroidoretinal atrophy, and capsular cataracts of no visual consequence, respectively.

One other child in the miscellaneous group, a girl aged 16 years, had colobomata of the iris and choroid; her visual defect had been unknown to her teachers and she was then certified as partially sighted. A third, a boy aged 15 years, had cataracts of no visual consequence.

* Received for publication March 24, 1966.

$\dagger$ Address for reprints: as above. 
Structural defects were therefore considerably more common than in the normal child population, including two blind children and one partially sighted out of sixty examined. There was little difference in this respect between the miscellaneous group (3) and the mongols (4).

The measurement of visual acuity for near and distance was performed, where possible, with the Sheridan Gardiner test.

It proved much more difficult to obtain results for near vision. Only eight of the miscellaneous group could perform the test (all normal), and thirty failed to understand the test or gave equivocal results. Amongst the mongols sixteen failed to grapple with the test, two obtained N5, and four were worse than this, one having an acuity as low as N12 (about the size of large typescript).

Table I shows the results for distance visual acuity.

TABLE I

Visual Acuity in Mongols and Other Mentally Handicapped Children

\begin{tabular}{ll|c|c}
\hline \multicolumn{2}{c|}{ Distance Visual Acuity } & Mongols & Others \\
\hline (a) Better than 6/12 in one or both eyes (with glasses where provided) & 5 & 13 \\
(b) $6 / 12$ or worse in the better eye (with glasses where provided) & 9 & 8 \\
(c) Unobtainable or equivocal & Total & 22 & 38 \\
\hline
\end{tabular}

Two of the miscellaneous group possessed glasses, one in group (a) and one in group $(b)$.

One of the mongols possessed glasses in group $(b)$.

None of the children in group $(c)$ possessed glasses.

Glasses were given to those who appeared to need them on grounds of refractive errors found, by analogy with normal children.

A total of sixteen mongols out of 22 (73 per cent.) had on this basis bilateral defective vision which in a normal child would have led to the consideration of glasses. Of these sixteen, one possessed glasses and fourteen were ordered them. The remaining child was blind with dense cataracts in both eyes.

Of the children with other mental handicaps, eleven (29 per cent.) were known or presumed to have bilateral defective vision. Of these eleven, two possessed glasses and seven were ordered glasses. Of the remaining two, one had a bilateral amblyopia of unknown origin and the other had bilateral congenital cataract, the best vision being 6/36 partly in one eye only.

Refraction showed that 50 per cent. of the mongols were myopic and 15 per cent. hypermetropic. This was in strong contrast with the other children, of whom only 3 per cent. were myopic and 40 per cent. hypermetropic. One of the children who had no glasses was a 6-year-old congenital myope who was -14D myopic in one eye and -10D in the other, so that her presumed visual acuity was considerably lower than the level required for statutory registration as blind.

Table II (opposite) shows the difference in distribution of astigmatism between the two groups. 
TABLE II

Distribution OF ASTIGMATISM (DIOPTRES)

\begin{tabular}{l|c|c|c|c|c|c|c|c|c}
\hline \multirow{2}{*}{ Group } & \multicolumn{2}{|c|}{0} & \multicolumn{2}{|c|}{$0.1 / 2$} & \multicolumn{2}{|c|}{$2.1 / 4$} & \multicolumn{2}{|c}{4} & \multirow{2}{*}{ Total } \\
\cline { 2 - 6 } \cline { 5 - 7 } & No. & per cent. & No. & per cent. & No. & per cent. & No. & per cent. & \\
\hline $\begin{array}{l}\text { Mongols } \\
\text { Others }\end{array}$ & 1 & 5 & 11 & 58 & 4 & 21 & 3 & 16 & 19 \\
\hline
\end{tabular}

Accurate assessment was not possible in three mongols and in eleven of the others, but five of the latter had normal visual acuity and the astigmatism if present would not be of a high order. Even if the remaining six had high astigmatic errors the proportion over 2 dioptres would still be less than 30 per cent. as compared with 37 per cent. of mongols.

Eight children in each group squinted, which meant a higher proportion amongst the mongols than the others.

Re-examination after a minimum of 3 months showed that, of the 21 children ordered glasses, fifteen were wearing them regularly. The failures were mostly amongst the younger children in the infants' class, but over 50 per cent. of these still wore their glasses.

\section{Discussion}

It was not surprising to find a high incidence of visual defect amongst these children but it was distressing that the difficulties of assessing its severity had previously seemed overwhelming, so that no treatment had been attempted and no information on its nature was available to the staff. The fact that 75 per cent. of the children continued to wear glasses ordered solely on the basis of correcting a refractive error found by retinoscopy shows not only that it is possible to provide acceptable glasses without subjective confirmation, but also that these children benefited in some way-though one cannot altogether discount pride of ownership as being one motive. This is hardly likely to outweigh visual difficulties due to poor prescribing if they were present, and in the case of two of the mongols with errors of $-6 \mathrm{D}$ and $-14 \mathrm{D}$ respectively, the difference in their environment must have been considerable enough to be noticed even by these children. One doubts if they would have continued wearing their lenses if this difference were intolerable. The logical and positive attitude to adopt is that a defect in one of the senses in addition to an intellectual or physical handicap may be a more crippling disadvantage to a defective child than to one who is otherwise normal.

The experiment shows that it is worth assuming that these children should be given the opportunity of seeing the world as others do, even if some fail to interpret it like normal children, or find it intolerable to do so.

From the point of view of developmental ophthalmology, the differences between the mongols and the others is of considerable interest.

In the first place the mongols show a very much higher incidence of visual defect and a difference in their nature. There was not much difference in the incidence of structural defects, but squints were slightly more common amongst the mongols. 
The most striking difference was that about 70 per cent. of the mongols had defective visual acuity (as judged by retinoscopy) compared with 30 per cent. of the others. This difference is largely accounted for by the greatly increased number of myopes amongst the mongols. It must, however, be noted that no fewer than $\mathbf{4 0}$ per cent. of the other children were hypermetropic. This corresponds closely to the incidence of hypermetropia amongst brain-damaged children at school for the physically handicapped (Fantl and Perlstein, 1961; Gardiner, 1963). It is also of interest to note that hypermetropia is more common than myopia amongst educationally subnormal children (Jevons, 1957).

Mongols are of course in a sense brain-damaged also, yet they show a preponderance of myopes. One should take into account the fact that a proportion of them have congenital heart lesions. Unfortunately in this series it was not possible to estimate the number or nature of these, so that the effect of this factor cannot be assessed. This may be of importance, because in a series of school children with cyanotic congenital heart lesions a higher proportion are myopic than amongst those with left to right shunts (unpublished data), and a higher proportion have other refractive anomalies-though not generally as gross as those found amongst the mongols.

The retinoscopy data also showed both an excessive incidence and a higher degree of astigmatism amongst the mongols-only 5 per cent. being unaffected as compared with 37 per cent. of the others.

The conclusion to which the evidence leads is that co-ordination of the optical elements during growth of the eye breaks down more frequently amongst mongols, though quite a high proportion of these eye conditions is likely to be congenital in origin in both groups. The breakdown is towards myopia in the one group and towards hypermetropia in the other.

The mongols are the anomalous group, because the evidence already cited suggests that defective cerebration is more often associated with hypermetropia during growth of the child. It is uncertain what part the associated factor of congenital heart disease may play in contributing towards the myopia.

Lowe (1949) found that 35 per cent. of 35 adult mongols were "highly" myopic, but said that difficulty in interpreting these figures arose from our profound ignorance concerning myopia in general. He also had difficulty in estimating the amount of astigmatism, but his figures show high astigmatic errors similar to those found in this survey. Because in the present survey 50 per cent. of the mongols were myopic, it seems probable that the myopia amongst the mongols is either congenital or ensues early in life. My opinion is that this is so when not complicated by lens changes and is non-progressive, but as already stated its relationship to the congenital heart lesions so common in mongolism needs to be further explored.

Contrary to these findings, Skeller and Øster (1951) found few myopes and Brushfield (1924) thought that the visual defects were due to hypermetropic astigmatism. These conflicting results suggest the possibility that different populations are being studied. The children in this report were all able to manage daily attendance at a training centre and to that extent the sample may not have been similar to those described by others.

Skeller and Øster (1951) also made the point confirmed in the present investigation 
that the social contact of these patients may depend greatly on their visual acuity, so that any abnormality therein requires consideration and treatment.

With regard to the general management of the visual problems of these children, the investigation brings out the value of examining these children at school. In common with physically-handicapped children they do not travel well and neither they nor the ophthalmologist are comfortable when the examination takes place in hospital. This is, no doubt, one of the reasons why so few of these children had been examined. One further advantage of conducting the examination at school is that the teacher can be informed directly of a child's difficulties instead of remaining unaware of them, which was the situation with the majority at this centre, or of having to rely on a parent's report.

How much difference clearer visual images are likely to make in the long run it is difficult to say, but before she was given glasses the 6-year-old high myope was thought to be excessively interested in her teacher's activities because she was always running up to see them close to. This at any rate shows a desire to see more clearly even after 6 years' conditioning otherwise. It is my opinion that this makes the case for at least one trial of glasses in those appearing to need them on grounds of gross refractive error. Because these children are so often illiterate it is sometimes forgotten that good near visual acuity may help them in other ways. Some of them can perform simple sewing tasks, but uncorrected hypermetropes find it difficult to thread a needle. Again, some can perform simple assembly tasks later in life of a fine nature which is helped by good visual acuity at the near point. Chosen cases should therefore become accustomed to wearing glasses as children while they are adaptable, so that they will be better able to undertake these types of activity in the future.

It seems that mongols form a group "at risk" of serious visual defects, and that in them, even more than in normal children, symptoms are likely to be suppressed or masked and therefore useless in detecting those who are actually handicapped. It is suggested that routine refraction should be performed on these children at an early age.

\section{Summary}

The incidence of visual defects is much higher in children with Down's syndrome than in children with other mental defects.

Serious structural defects were found in both groups but the greatest difference was in the incidence and nature of the refractive errors.

The high incidence of hypermetropia in the group of children with miscellaneous mental defects is in line with previous studies of educationally subnormal and braindamaged children.

The high incidence of myopia amongst those with Down's syndrome needs to be further investigated, taking into account their other congenital lesions.

Some observations are made on the ophthalmic management of such children, particularly with regard to the advantage to them of more accurate vision, and the consequent need for refraction at an early age. 
This work was carried out by courtesy of Dr. Wigley, when Principal Medical Officer of the Middlesex County Council, and continued by Dr. Grundy, Medical Officer of Health, London Borough of Brent. I owe thanks to them, to Mrs. Lerry, headmistress and initiator of the investigation, and to her staff and pupils.

\section{REFERENCES}

Brushfield, T. (1924). Brit. J. Child. Dis., 21, 241.

Fantl, E. W., and Perlstein, M. A. (1961). Amer. J. Dis. Child., 102, 36.

Gardiner, P. A. (1963). "Visual Disorders and Cerebral Palsy", ed. V. H. Smith. Little Club Clinics in Developmental Medicine, No. 9, p. 44.

Jevons, N. A. (1957). Med. Offr, $97,53$.

LOWE, R. F. (1949). Brit. J. Ophthal., 33, 131.

SKeller, E., and Øster, J. (1951). Acta ophthal. (Kbh.), 29, 149. 